\title{
Assessment of Genetic Susceptibility to Multiple Primary Cancers through Whole-Exome Sequencing in Two Large Multi-Ancestry Studies
}

Taylor B. Cavazos ${ }^{1}$, Linda Kachuri², Rebecca E. Graff ${ }^{2,3}$, Jovia L. Nierenberg ${ }^{2,5}$, Khanh K. Thai ${ }^{3}$, Stacey Alexeeff ${ }^{3}$, Stephen Van Den Eeden ${ }^{3}$, Douglas A. Corley ${ }^{3}$, Lawrence H. Kushi ${ }^{3}$, Regeneron Genetics Center ${ }^{4}$, Thomas J. Hoffmann $^{2}$, Elad Ziv ${ }^{5}$, Laurie Habel ${ }^{3}$, Eric Jorgenson ${ }^{4}$, Lori C. Sakoda ${ }^{3,6}$, and John S. Witte ${ }^{2,7,8}$

\section{Affiliations:}

${ }^{1}$ Biological and Medical Informatics, University of California San Francisco, San Francisco, CA 94158

2 Department of Epidemiology and Biostatistics, University of California San Francisco, San Francisco, CA 94158

${ }^{3}$ Division of Research, Kaiser Permanente Northern California, Oakland, CA 94612

${ }^{4}$ Regeneron Genetics Center, Tarrytown, New York 10591

${ }^{5}$ Department of Medicine, University of California San Francisco, San Francisco, CA 94158

${ }^{6}$ Department of Health Systems Science, Kaiser Permanente Bernard J. Tyson School of Medicine, Pasadena, CA 91101

${ }^{7}$ Department of Epidemiology and Population Health, Stanford University, Stanford, CA 94305

${ }^{8}$ Department of Biomedical Data Science, Stanford University, Stanford, CA 94305

\section{Corresponding Author:}

John S. Witte

Department of Epidemiology and Population Health

Alway Building, Stanford University

300 Pasteur Drive, Stanford, CA 94305

Phone: (415) 502-6882

Email: jswitte@stanford.edu

\section{CONFLICTS OF INTERESTS}

J.S. Witte is a non-employee, cofounder of Avail Bio. E. Jorgenson and additional authors listed under "Regeneron Genetics Center" are full-time employees of Regeneron Pharmaceuticals. No disclosures were reported for the other authors.

Word Count: 4,217

Figures/ Tables: 4

NOTE: This preprint reports new research that has not been certified by peer review and should not be used to guide clinical practice. 
medRxiv preprint doi: https://doi.org/10.1101/2022.02.11.22270688; this version posted February 15, 2022. The copyright holder for this preprint (which was not certified by peer review) is the author/funder, who has granted medRxiv a license to display the preprint in perpetuity.

It is made available under a CC-BY-NC 4.0 International license.

\section{ABSTRACT}

Up to one of every six individuals diagnosed with one cancer will be diagnosed with a second primary cancer in their lifetime. Genetic factors contributing to the development of multiple primary cancers, beyond known cancer syndromes, have been underexplored. To characterize genetic susceptibility to multiple cancers, we conducted a pan-cancer, whole-exome sequencing study of individuals drawn from two large prospective cohorts (6,429 cases, 165,853 controls). We created two groupings of individuals diagnosed with multiple primary cancers: 1) an overall combined set with at least two cancers across any of 36 organ sites; and 2) cancer-specific sets defined by an index cancer at one of 16 organ sites with at least 50 cases from each study population. We then investigated whether variants identified from exome sequencing were associated with these sets of multiple cancer cases in comparison to individuals with one and, separately, no cancers. We identified 22 variant-phenotype associations, 10 of which have not been previously discovered and were significantly overrepresented among individuals with multiple cancers, compared to those with a single cancer. Overall, we describe variants and genes that may play a fundamental role in the development of multiple primary cancers and improve our understanding of shared mechanisms underlying carcinogenesis. Further investigation of these findings may lead to new screening strategies for individuals at risk for multiple primary cancers. 
medRxiv preprint doi: https://doi.org/10.1101/2022.02.11.22270688; this version posted February 15, 2022. The copyright holder for this preprint (which was not certified by peer review) is the author/funder, who has granted medRxiv a license to display the preprint in perpetuity.

It is made available under a CC-BY-NC 4.0 International license .

\section{INTRODUCTION}

2 The substantial global burden of cancer coupled with increasing survival due to improved 3 screening, surveillance, and treatments has yielded a growing number of cancer survivors who

4 are at risk of developing a second primary cancer in their lifetime ${ }^{1,2}$. The prevalence of multiple

5 primary cancers globally is estimated to be between 2 and $17 \%$, with the wide range likely due to

6 differences in cancer registration practices, case definitions, population characteristics, and

7 follow-up times ${ }^{1,2}$. Cancer predisposition syndromes, such as Li-Fraumeni, Lynch, and hereditary

8 breast and ovarian cancer, are known to increase the risk of multiple primary cancers; however,

9 less than $2 \%$ of all cancers are attributed to hereditary cancer syndromes ${ }^{1}$. Genetic risk factors

10 for multiple primary cancers beyond known syndromes are not well understood.

Genome-wide association studies (GWAS) have implicated many common, low penetrance variants in 5p15 (TERT-CLPTM1L) $)^{3}, 6 \mathrm{p} 21(H L A)^{4,5}, 8 \mathrm{q} 24^{6}$, and other loci in the risk of several cancer types. Additional studies have investigated pleiotropy in these regions or characterized cross-cancer susceptibility variants ${ }^{7,8}$. A pleiotropic locus has the potential to not only affect risk of many different cancer types, but also increase the likelihood that a single individual develops multiple primary cancers. In our prior work, we discovered that the rare pleiotropic variant HOXB13 G84E had a stronger association with the risk of developing multiple primary cancers than of a single cancer ${ }^{9}$. This suggests that there may be increased power to detect pleiotropic variation in individuals with multiple primary cancers relative to those with only a single cancer.

21 Identifying widespread pleiotropic signals is informative for understanding shared genetic 22 mechanisms of carcinogenesis, toward the identification of informative markers for cancer 23 prevention and precision medicine.

25 In this study, we survey the landscape of rare and common variation in individuals with multiple 26 primary cancers, single cancers, and cancer-free controls through whole-exome sequencing 
medRxiv preprint doi: https://doi.org/10.1101/2022.02.11.22270688; this version posted February 15, 2022. The copyright holder for this preprint (which was not certified by peer review) is the author/funder, who has granted medRxiv a license to display the preprint in perpetuity.

It is made available under a CC-BY-NC 4.0 International license .

27 (WES) in two large, multi-ancestry studies. We evaluate associations previously discovered in

28 studies of individuals with a single cancer and find novel pleiotropic variation in individuals with

29 multiple primaries.

31 MATERIAL AND METHODS

\section{Study Populations and Phenotyping}

33 Our study included ancestrally diverse individuals with multiple primary cancers or no cancer from

34 two large prospective studies: the Kaiser Permanente Research Bank (KPRB) and the UK

35 Biobank (UKB). From the KPRB, we included individuals who were previously genotyped through

36 the Research Program on Genes, Environment and Health (RPGEH) and the ProHealth Study.

37 For the UKB, we specifically studied participants from the $200 \mathrm{~K}$ release of WES data, which also included individuals diagnosed with a single cancer $^{10}$.

40 For both study populations, ascertainment of cancer diagnoses has been previously

41 described ${ }^{11,12}$. Both studies included prevalent and incident diagnoses of malignant, borderline,

42 and in situ primary tumors ${ }^{12}$. ICD codes indicating non-melanoma skin cancer or metastatic

43 cancer were not considered primary tumors. Cancers were primarily defined according to the

44 SEER site recode paradigm ${ }^{13}$. However, for hematologic cancers, we incorporated morphology

45 following WHO classifications ${ }^{14}$, placing cancers into three major subtypes: Iymphoid neoplasms,

46 myeloid neoplasms, and NK- and T-cell neoplasms (Table S1). Cases were individuals with ICD-

479 or ICD-10 codes for primary tumors at two or more distinct organ sites. In the KPRB, controls

48 without a cancer diagnosis were matched 1:1 to cases on age at specimen collection, sex, 49 genotyping array (which matched on self-reported race/ethnicity), and reagent kit. In the UKB, 50 controls included all individuals without a cancer diagnosis. 
medRxiv preprint doi: https://doi.org/10.1101/2022.02.11.22270688; this version posted February 15, 2022. The copyright holder for this preprint (which was not certified by peer review) is the author/funder, who has granted medRxiv a license to display the preprint in perpetuity.

It is made available under a CC-BY-NC 4.0 International license.

52 In both study populations, we excluded duplicates/twins and first-degree relatives, retaining the

53 individual from each related pair who had higher coverage at targeted sites. Following quality

54 control (QC) of WES data (described below), the KPRB and UKB study populations used in this

55 project included 3,111 and 3,318 cases with multiple primary cancers and 3,136 and 162,717

56 cancer-free controls, respectively. The UKB also contributed 29,091 individuals with a single

57 cancer diagnosis. While our study was primarily unselected for cancer type, prostate cancer cases

58 were oversampled in the KPRB due to inclusion of individuals from the ProHealth Study.

\section{Genetic Ancestry and Principal Components Analysis}

61 Genetic ancestry was defined using genome-wide, imputed array data that underwent extensive

62 QC, as previously described ${ }^{12}$. Ancestry principal components (PCs) were computed using

63 flashPCA2 $2^{15}$ by projecting our study samples onto PCs defined by $1000 \mathrm{G}$ phase 3 reference

64 populations ${ }^{16}$. Individuals were assigned to the closest reference population using distance from

65 the top 10 PCs. Individuals with ancestral PCs greater than five standard deviations from the

66 reference population mean were excluded. The final analytic dataset included individuals of

67 European, African, East Asian, South Asian, and Hispanic/Latino ancestry (Figure S1). A total of

$68 \mathrm{~N}=646(10.2 \%)$ and $\mathrm{N}=8,739(5.26 \%)$ individuals were of non-European ancestry in the KPRB

69 and UKB, respectively (Table 1).

\section{Whole-Exome Sequencing and Quality Control}

72 The Regeneron Genetics Center used the Illumina NovaSeq 6000 platform to perform WES for

73 both study populations. Sample preparation and QC were performed using a high-throughput,

74 fully-automated process that has been previously described in detail ${ }^{17}$. Briefly, following 75 sequencing, reads were aligned to the GRCh38 reference genome and variants were called with

76 WeCall ${ }^{17}$ for the KPRB and DeepVariant ${ }^{18}$ for the UKB. Samples with gender discordance, 20x 77 coverage at less than $80 \%$ of targeted sites, and/or contamination greater than $5 \%$ were excluded. 
medRxiv preprint doi: https://doi.org/10.1101/2022.02.11.22270688; this version posted February 15, 2022. The copyright holder for this preprint (which was not certified by peer review) is the author/funder, who has granted medRxiv a license to display the preprint in perpetuity.

It is made available under a CC-BY-NC 4.0 International license .

79 Additional QC was applied to filter low quality variants and related individuals. First, genotype 80 calls with low depth of coverage (DP) were updated to missing (DP $<7$ for SNPs and DP $<10$ for

81 indels). Then, sites with low allele balance (AB) were removed. Specifically, variants without at

82 least one sample having $A B \geq 15 \%$ for SNPs or $A B \geq 20 \%$ for indels were excluded. Additionally, 83 variants with missingness $>10 \%$ and HWE $p$-value $<10^{-15}$ were excluded. Following these steps,

84 a total of $\sim 3.51 \mathrm{M}$ high-quality sites were retained for the KPRB and $\sim 15.92 \mathrm{M}$ were retained for

85 the UKB; excluding singletons, there were $\sim 1.36 \mathrm{M}$ and $\sim 8.22 \mathrm{M}$ variants, respectively. In the UKB,

86 the larger number of variants observed was due to rare variation present in the larger sample

87 size; when restricting to common variants (MAF > 1\%), there were $\sim 186 \mathrm{~K}$ and $\sim 137 \mathrm{~K}$ variants, 88 respectively for the KPRB and UKB.

\section{Association Analyses in Individuals with Multiple Cancers versus Cancer-Free Controls}

91 Genetic association analyses of single variants and genes investigated the following cancer

92 phenotypes: (1) diagnosis with at least two primary cancers across any of the 36 organ sites ("any

$932+$ primary cancers") and (2) groupings of individuals defined by a shared index cancer at one of

9416 organ sites with at least 50 cases from each study population. ("cancer-specific analyses").

95 Primary analyses compared multiple cancer cases to cancer-free controls. Within our cancer-

96 specific analyses of 16 organ sites, there were cases shared across our index cancer groupings.

97 For example, the set of individuals with at least one diagnosis of breast cancer overlaps with those

98 having at least one ovarian cancer diagnosis.

100 Single-variant and gene-based association analyses were performed using REGENIE v2.2.4, a 101 machine-learning approach for performing whole-genome regression that adjusts for case-control 102 imbalance by applying saddlepoint approximation when the standard case-control p-value is less 103 than $0.05^{19}$. We assessed single-variant associations for high-quality variants with minor allele 
medRxiv preprint doi: https://doi.org/10.1101/2022.02.11.22270688; this version posted February 15, 2022. The copyright holder for this preprint (which was not certified by peer review) is the author/funder, who has granted medRxiv a license to display the preprint in perpetuity.

It is made available under a CC-BY-NC 4.0 International license .

104

105

106

107

108

109

110 population (Supplements).

count $(\mathrm{MAC})>2$. WES variants were functionally annotated using SnpEff $v 5.0^{20}$ and dbNFSP $\mathrm{v} 3.5^{21}$ accessed through ANNOVAR ${ }^{22}$. Missense variants were classified using five algorithms: (1) SIFT (“D”); (2) HDIV from Polyphen2; (3) HVAR from Polyphen2; (4) LRT (“D”); and (5) MutationTaster ("A" or "D"). For our gene-based burden analyses, we used three minor allele frequency cut-offs (MAF $<0.5 \%, 1 \%$, or $5 \%$ ), including singletons, computed within each population. Following previous work, three gene-based models were evaluated ${ }^{23}$ : (1) all rare variants with predicted loss-of-function (pLOF) by SnpEff, (2) pLOF and missense rare variants predicted to be deleterious by the above five classification algorithms, and (3) pLOF and missense rare variants predicted to be deleterious by at least one algorithm. Out of all allele frequency and burden combinations, we report the burden test with the lowest p-value. In the case of ties, we report the most restrictive grouping (fewest number of variants included). In our gene-based and single-variant analyses, we adjusted for covariates including age, top 10 PCs, and sex (except for sex-specific index cancers of the breast, cervix, ovary, uterus, other female genital organ, and prostate). In the KPRB population, we additionally adjusted for genotyping array and reagent kit, as they were used to perform case-control matching. In the UKB, we adjusted for flow cell (S2 vs S4), which differed for the initial $50 \mathrm{~K}$ and subsequent $150 \mathrm{~K}$ release of WES samples.

Single-variant and gene-based burden analyses for each phenotype were combined across study populations in a fixed-effects meta-analysis using METASOFT ${ }^{24}$ and metafor v3.0.2 ${ }^{25}$, respectively. For our single-variant analyses, we report all suggestive, independent [linkage disequilibrium (LD) $r^{2}<0.2$ ] associations with $p<5 \times 10^{-6}$. For our gene-based analyses, we report all associations adjusted for the number of genes tested $\left(p<2.65 \times 10^{-6}=0.05 / 18,842\right)$. We report meta-analysis p-values (Main Text), except when a variant was unique to a single study 
medRxiv preprint doi: https://doi.org/10.1101/2022.02.11.22270688; this version posted February 15, 2022. The copyright holder for this preprint (which was not certified by peer review) is the author/funder, who has granted medRxiv a license to display the preprint in perpetuity.

It is made available under a CC-BY-NC 4.0 International license .

130 We also evaluated whether the variants and genes associated with the diagnosis of multiple 131 primary cancers (versus non-cancer controls) remained associated when comparing individuals 132 with multiple cancers to those diagnosed with a single cancer. These analyses assessed whether 133 the variants or genes were pleiotropic for developing multiple cancers or general markers of 134 susceptibility to a specific cancer. We undertook these analyses in the UKB sample only, since 135 individuals diagnosed with a single primary cancer were not sequenced in the KPRB. Single136 variant and gene-level analyses were implemented as described above. For each variant or gene 137 of interest identified in our case-control analyses, we performed a case-case analysis comparing 138 individuals diagnosed with multiple cancers to those diagnosed with a single cancer. For our cancer-specific analyses, we compared individuals diagnosed with the index cancer plus any other cancer to those diagnosed with the index cancer only. For example, for a finding discovered in our cancer-specific analysis of prostate cancer, we performed a case-case analysis comparing individuals diagnosed with prostate cancer plus any other cancer to individuals with only a prostate cancer diagnosis.

\section{RESULTS}

\section{Characterization of Multiple Primary Cancer Diagnoses in Two Large Study Populations}

147 Our meta-analyses included 6,429 cases with multiple primary cancers and 165,853 cancer-free

148 controls (Table 1). All cases had at least two independent primary cancer diagnoses, and 656 149 cases had more than two diagnoses (Figure S2). In the KPRB, the maximum number of cancer 150 diagnoses for an individual was $6(n=1)$ and in the UKB, the maximum number was $5(n=2)$.

151 Overall, 36 unique cancer sites were represented across multiple cancer cases in the two study 152 populations, with 180 unique pairs of sites (e.g., breast and melanoma) and 298 unique pairs of 153 sites and diagnostic sequence (e.g., breast followed by melanoma) (Table S2). Only 51 of the

154298 ordered pairs had at least 25 cancer cases when grouping individuals by first and second 155 cancer diagnosis (i.e., ignoring any subsequent cancer diagnoses; Table S2, Figure 1). The top 
medRxiv preprint doi: https://doi.org/10.1101/2022.02.11.22270688; this version posted February 15, 2022. The copyright holder for this preprint (which was not certified by peer review) is the author/funder, who has granted medRxiv a license to display the preprint in perpetuity.

It is made available under a CC-BY-NC 4.0 International license .

ordered pairs represented in the combined study populations were prostate then melanoma $(\mathrm{N}=$ 221), cervix then breast $(N=202)$, melanoma then prostate $(N=180)$, breast then melanoma $(N$ $=174)$, and prostate then colorectal $(\mathrm{N}=170)$. Prostate, breast, melanoma, colorectal, and cervix were the most common sites of first cancer diagnoses (Figure 1). The prevalence of each cancer pair was similar in the KPRB and UKB (Figure S3). As most individual cancer pairs were underpowered for downstream analysis, we considered all multi-cancer cases combined, as well as groupings of individuals with a shared index cancer (16 cancers) (Figure S4, Table S3). Among

163 those with multiple cancers, the cancers with the largest number of cases were prostate $(\mathrm{N}=$ $1641,977$; oversampled in $\mathrm{KPRB})$, breast $(\mathrm{N}=1,874)$, melanoma $(\mathrm{N}=1,443)$, colorectal $(\mathrm{N}=1,324)$, and urinary bladder $(\mathrm{N}=829)$.

\section{Exome-wide Single Variant Association Analyses}

168 We found 22 associations $\left(p<5 \times 10^{-6}\right)$ between individual variants and the multiple cancer phenotypes (i.e., either any 2+ primary cancers or cancer-specific analyses) (Figure 2, Table S4). We found an additional four associations (Figure S5) in our cancer-specific analyses of lymphoid

171 and myeloid neoplasms; however, we assumed them to represent somatic alterations in the blood 172 as they had low allele balance across our heterogenous samples (Figure S6) and occur in genes 173 known to be impacted by clonal hematopoiesis of indeterminate potential $(\mathrm{CHIP})^{26}$. Results were 174 relatively homogeneous across the KPRB and UKB study populations (Table S4).

We detected two variants associated with any $2+$ primary cancers, rs555607708 $(\mathrm{OR}[95 \% \mathrm{Cl}]=$

$\left.1772.72[1.79,4.15], p=3.10 \times 10^{-6}\right)$, a frameshift variant in CHEK2 known to be associated with risk 178 at many cancer $\operatorname{sites}^{27}$, and $\operatorname{rs} 146381257\left(\mathrm{OR}[95 \% \mathrm{Cl}]=7.82[3.28,18.62], \mathrm{p}=3.45 \times 10^{-6}\right), a$ 179 5'upstream variant in ZNF106. The risk-increasing allele for rs555607708 (CHEK2) was most 180 commonly found among individuals with at least one breast cancer (41.9\%), prostate cancer 181 (30.6\%), melanoma (22.6\%), or cervical cancer (16.1\%) (Figure 2). For rs146381257 (ZNF106), 
medRxiv preprint doi: https://doi.org/10.1101/2022.02.11.22270688; this version posted February 15, 2022. The copyright holder for this preprint (which was not certified by peer review) is the author/funder, who has granted medRxiv a license to display the preprint in perpetuity.

It is made available under a CC-BY-NC 4.0 International license .

182 frequencies were increased in prostate cancer (33.3\%), lung cancer $(28.6 \%)$, breast cancer 183 (28.6\%), lymphoid neoplasms (23.8\%), urinary bladder cancer (19.0\%), pancreatic cancer 184 (14.3\%), and kidney cancer (14.3\%).

186 Cancer-specific analyses identified 10 associations between previously reported risk variants for 187 a single cancer and risk of diagnosis with that cancer plus any other cancer (Figure 2). Notably, 188 we detected an association with the $M C 1 R$ variant $\mathrm{rs} 1805008$ for melanoma ${ }^{28}(\mathrm{OR}[95 \% \mathrm{Cl}]=$ $\left.1891.56[1.35,1.81], p=2.73 \times 10^{-9}\right)$, when comparing all individuals with at least one melanoma 190 diagnosis plus any other cancer diagnosis to cancer-free controls. We also replicated the 191 previously associated prostate-specific antigen (PSA) variant, rs $17632542^{29}(K L K 3, \mathrm{OR}[95 \% \mathrm{Cl}]$ $\left.192=1.49[1.28,1.73], p=3.87 \times 10^{-7}\right)$ in individuals with at least one prostate cancer diagnosis. In 193 addition, we replicated associations between missense risk variant rs6998061 (8q24 locus, 194 POU5F1B) and multiple tumor types in both our prostate cancer-specific analysis ${ }^{30}(\mathrm{OR}[95 \% \mathrm{Cl}]$ $\left.195=1.23[1.13,1.33], \mathrm{p}=4.39 \times 10^{-7}\right)$ and our colorectal cancer-specific analysis ${ }^{31}(\mathrm{OR}[95 \% \mathrm{Cl}]=$ $\left.1.25[1.15,1.37], p=1.06 \times 10^{-7}\right)$.

The remaining variants demonstrating associations with multiple cancer phenotypes were not previously associated with any single cancer (Figure 2). They included a variant discovered in our breast cancer-specific analysis, rs143745791 (NCBP1, OR [95\% Cl] $=5.95[2.79,12.67], \mathrm{p}=$ $\left.3.76 \times 10^{-6}\right)$, for which $16.2 \%$ of carriers, restricted to cases, had a breast and cervical cancer 202 diagnosis, and a variant discovered in our urinary bladder cancer-specific analysis, rs141647689 $203\left(S D K 1\right.$, OR $\left.[95 \% \mathrm{Cl}]=9.29[3.63,23.80], \mathrm{p}=3.45 \times 10^{-6}\right)$, for which $14.3 \%$ of carriers also had 204 prostate cancer (Figure 2). Three variants found in our lymphoid neoplasm-specific analysis had 205 increased frequencies in cases who also had a diagnosis of prostate cancer: rs535484207 $206\left(R A N B P 2\right.$, OR $\left.[95 \% \mathrm{Cl}]=256.01[26.82,2,442.95], \mathrm{p}=1.46 \times 10^{-6}\right), \mathrm{rs} 139586367(U F L 1$, OR $[95 \%$ $\left.207 \mathrm{Cl}]=284.06[27.95,2,886.15], \mathrm{p}=1.79 \times 10^{-6}\right)$, and $\mathrm{rs} 191064896($ ADGRB1, OR $[95 \% \mathrm{Cl}]=108.36$ 
medRxiv preprint doi: https://doi.org/10.1101/2022.02.11.22270688; this version posted February 15, 2022. The copyright holder for this preprint (which was not certified by peer review) is the author/funder, who has granted medRxiv a license to display the preprint in perpetuity.

It is made available under a CC-BY-NC 4.0 International license .

[15.02, 781.08], $\left.p=3.32 \times 10^{-6}\right)$, where $21.4 \%, 40.0 \%$, and $25.0 \%$ of carriers for the risk-increasing

allele, for each respective variant, had both cancers. The $A D G R B 1$ variant was also present at increased frequencies among individuals with a lymphoid neoplasm and breast cancer diagnosis

$211(25.0 \%$, Figure 2).

\section{Gene-Based Analyses of Multiple Cancers}

214 Out of 18,842 genes tested, we found 11 significant associations $\left(p<2.65 \times 10^{-6}\right)$ across our 215 analyses of any 2+ primary cancers and our cancer-specific analyses (Figure 3, Table S5). An 216 additional four CHIP genes ( $A S X L 1, T E T 2$, JAK2, and DDX41) were significantly associated with 217 myeloid neoplasms and are likely driven by somatic alterations (Figure S7).

In our analyses of any 2+ primary cancers and our breast cancer-specific analysis, we replicated

associations for known pleiotropic genes, BRCA2 ( $p L O F, p=3.76 \times 10^{-11}$ and $1.91 \times 10^{-9}$ ) and analysis ( $\mathrm{pLOF}+$ missense, $\mathrm{p}=9.84 \times 10^{-7}$ and $2.56 \times 10^{-6}$ ). Additional associations were observed between SAMHD1 and SLC642 and any 2+ primary cancers (pLOF + missense, $p=2.40 \times 10^{-7}$ and $p=5.44 \times 10^{-7}$, respectively). BRCA1 also surfaced in the breast cancer-specific analysis (pLOF, $\mathrm{p}=6.68 \times 10^{-8}$ ), as did AHCTF1 in the head and neck cancer-specific analysis (pLOF + missense, $p=1.25 \times 10-6)$.

230 Functional variants in $B R C A 1$ and $B R C A 2$ were present at increased frequencies in individuals 231 with a breast cancer diagnosis and ovary as an additional cancer site (Figure 3), such that $28.6 \%$ 232 and $13.6 \%$ of individuals, respectively, were a carrier for at least one variant in the burden set. 233 For BRCA1, there was also an increase of carriers with an additional melanoma (9.52\%) or lung 
medRxiv preprint doi: https://doi.org/10.1101/2022.02.11.22270688; this version posted February 15, 2022. The copyright holder for this preprint (which was not certified by peer review) is the author/funder, who has granted medRxiv a license to display the preprint in perpetuity.

It is made available under a CC-BY-NC 4.0 International license .

234 cancer $(9.52 \%)$ diagnosis. For $B R C A 2$, there was an increase of carriers with an additional uterine $235(8.47 \%)$, lung $(6.78 \%)$, or colorectal cancer $(6.78 \%)$.

\section{Comparison of Mutation Burden in Individuals with Multiple versus Single Cancers}

238 Out of the 22 associated variants (above), 10 remained associated when comparing individuals 239 with multiple cancers to those with single cancers (Table S6; $p<0.05$ ). Two of these variants 240 were positively associated in our analysis of any 2+ primary cancers: rs555607708 (CHEK2; OR $241[95 \% \mathrm{Cl}]=1.57[1.09,2.25], \mathrm{p}=0.015)$ and $\mathrm{rs} 146381257($ ZNF106; OR $[95 \% \mathrm{Cl}]=5.38[1.07$

242 27.18], $p=0.042)$. The other eight variants were positively associated with diagnosis of a specific 243 index cancer plus any other cancer versus the specific cancer alone (Table S6). Two of these 244 eight variants were associated in our breast cancer-specific case-case analysis: rs7872034, a missense variant in SMC2 $(\mathrm{OR}[95 \% \mathrm{Cl}]=1.16[1.05,1.27], \mathrm{p}=0.0025)$ and $\mathrm{rs} 143745791, \mathrm{a}$ missense variant in NCBP1 (OR $\left.[95 \% \mathrm{Cl}]=3.71[2.08,6.61], \mathrm{p}=8.37 \times 10^{-6}\right)$.

Of the 11 findings from the gene-level burden analyses (above), seven remained positively associated with multiple cancers in comparison with single cancers $(p<0.05$; Table S7). Four of these genes were discovered in our case-case analysis of any 2+ primary cancers: ATM (OR $[95 \% \mathrm{Cl}]=1.20[1.06,1.36], \mathrm{p}=0.00399), \operatorname{CHEK} 2\left(\mathrm{OR}[95 \% \mathrm{Cl}]=1.56[1.23,1.98], \mathrm{p}=2.31 \times 10^{-}\right.$

$\left.{ }^{4}\right), \operatorname{SAMHD} 1\left(\mathrm{OR}[95 \% \mathrm{Cl}]=1.56[1.14,2.13], \mathrm{p}=5.34 \times 10^{-3}\right)$, and $B R C A 2(\mathrm{OR}[95 \% \mathrm{Cl}]=1.86$ associated in our prostate cancer-specific case-case analysis, and the two remaining genes were positively associated in our breast cancer-specific case-case analysis: $B R C A 1(\mathrm{OR}[95 \% \mathrm{Cl}]=$ $2.38[1.07,5.30], p=0.034)$ and $B R C A 2(\mathrm{OR}[95 \% \mathrm{Cl}]=1.97[1.22,3.18], \mathrm{p}=0.0055)$. 
medRxiv preprint doi: https://doi.org/10.1101/2022.02.11.22270688; this version posted February 15, 2022. The copyright holder for this preprint (which was not certified by peer review) is the author/funder, who has granted medRxiv a license to display the preprint in perpetuity.

It is made available under a CC-BY-NC 4.0 International license .

259 We investigated the genetic basis of carcinogenic pleiotropy through whole exome sequencing of

260 individuals diagnosed with multiple primary cancers from two large, multi-ancestry study

261 populations. Comparing individuals with multiple cancers to cancer-free controls uncovered 22

262 independently associated variants, ten of which remained associated when comparing individuals

263 with multiple cancers to those with a single cancer. We also found significant associations

264 between the genes AHCTF1, ATM, BRCA1/2, CHEK2, SAMHD1, and SLC6A2 and our multiple

265 cancer phenotypes. Other than AHCTF1 and SLC6A2, these genes remained associated with

266 multiple cancer diagnoses when comparing to individuals with a single cancer. These findings

267 offer insights into germline exome variants that increase an individual's risk of developing multiple

268 primary cancers.

270 Compelling findings from our analyses of all individuals with more than one cancer diagnosis

271 include associations with the rare variant rs146381257 in ZNF106. Carriers of the rs146381257

272 risk allele $(\mathrm{C})$ were primarily over-represented in individuals with at least one prostate, breast,

273 lung, or urinary bladder cancer and in individuals with lymphoid neoplasms. Carriers also

274 demonstrated an increased risk of developing multiple cancers compared to individuals with a

275 single cancer. ZNF106 is an RNA binding protein involved in post-transcriptional regulation and

276 insulin receptor signaling. Although germline variation in ZNF106 has not previously been

277 associated with cancer risk, a recent study found it to be associated with worse urinary bladder

278 cancer survival ${ }^{32}$.

280 Additional noteworthy findings from our analyses of all multiple primary cancers combined include

281 cancer susceptibility signals in SAMHD1 and SLC6A2. Carriers of rare and potentially deleterious

282 variants in $S A M H D 1$, a gene with a plausible tumor suppressor role ${ }^{33}$, had a significantly higher

283 risk being diagnosed with multiple cancers compared to single cancers. Germline SAMHD1

284 mutations are implicated in Aicardi-Goutieres Syndrome (AGS) ${ }^{34}$, an autosomal recessive 
medRxiv preprint doi: https://doi.org/10.1101/2022.02.11.22270688; this version posted February 15, 2022. The copyright holder for this preprint (which was not certified by peer review) is the author/funder, who has granted medRxiv a license to display the preprint in perpetuity.

It is made available under a CC-BY-NC 4.0 International license .

condition that results in autoimmune inflammatory encephalopathy. Most cancer-related studies

have focused on the role of somatic alternations in $S A M H D 1^{35}$. However, a study of chronic

287 lymphoid leukemia (CLL) proposed an oncogenic role of germline SAMHD1 variation mediated 288 by DNA repair mechanisms ${ }^{36}$. Consistent with this hypothesis, we also found increased SAMHD1

289 variation in individuals with lymphoid neoplasms, as well as with prostate, breast, colorectal and 290 lung cancers. SLC6A2, also known as NAT1, has been found to be prognostic for colon cancer ${ }^{37}$, 291 and both in-vivo and in-vitro studies have linked expression to survival in many cancer types, 292 including prostate ${ }^{38}$ and breast ${ }^{39}$. Polymorphisms in SLC6A2 may also interact with smoking 293 exposure to modulate risk for tobacco-related cancers ${ }^{40}$. In our study, the increased cancer risk detected among SLC6A2 carriers was limited to comparisons with cancer-free controls.

Because we compared multiple primary cancers with both cancer-free controls and individuals rs7872034 (missense variant in SMC2) and rs143745791 (missense variant in NCBP1), associated with a diagnosis of at least one breast cancer (plus any other cancer) versus no cancer. These variants remained associated with a diagnosis of breast and another cancer when comparing to individuals diagnosed with a single breast cancer. While rs7872034 is in high LD $(r 2=0.98)$ with a known breast cancer risk variant (rs4742903; SMC2 intron) ${ }^{41}$, it may also

304 increase the risk of developing multiple cancers. Regarding rs143745791, germline variants in 305 NCBP1 have not been previously associated with cancer; because it is rare (MAF $<0.2 \%$ ), larger 306 sequencing efforts may be necessary identify variation in studies of individuals with a single 307 cancer. Expression of this gene has been found to promote lung cancer growth and poor 308 prognosis $^{42}$, and NCBP1 is overexpressed in basal-like and triple-negative breast cancers ${ }^{43}$. 309 Similarly, BRCA1/2 germline variants are prevalent among these subtypes; however, in our study 
medRxiv preprint doi: https://doi.org/10.1101/2022.02.11.22270688; this version posted February 15, 2022. The copyright holder for this preprint (which was not certified by peer review) is the author/funder, who has granted medRxiv a license to display the preprint in perpetuity.

It is made available under a CC-BY-NC 4.0 International license .

310 populations, BRCA1/2 carriers were more common among those with an additional ovarian

311 cancer whereas NCBP1 carriers more frequently had an additional cervical cancer.

313 In our prostate cancer-specific analysis comparing individuals with multiple cancers versus those

314 with only a single cancer, we discovered an association with rs3020779, an eQTL for RNF123

315 (also known as KPC1), which is a gene involved in p50 mediation and downstream stimulation of 316 multiple tumor suppressors ${ }^{44}$. In our analysis of head and neck cancer, we detected an 317 association with rs12253181 (eQTL for RTKN2); while this gene has not previously been 318 associated with head and neck cancer risk, it has been shown to function as an oncogene in non319 small cell lung cancer (NSCLC) and decreasing its expression may inhibit proliferation by inducing 320 apoptosis $^{45}$.

Limitations of our study included the identification of variants that were likely-somatic in our analyses of hematologic cancers due to an expansion of hematopoietic clonal populations with

324 the same acquired mutation (i.e., CHIP). Confounding of germline testing by CHIP has been 325 reported in $T P 53^{46}$ and $T E T 2^{47}$, so careful interpretation is critical to avoid unnecessary clinical 326 intervention. An additional limitation of our, and other, studies are obtaining accurate effects 327 estimates for rare variants and the reliance on available annotations for inclusion into gene-based 328 tests. Replication of rare findings in larger cohorts and optimization of functional impact 329 annotations could lead to more precise results. Also, while our approach did not allow for formal 330 replication, it was designed to identify signals for a largely understudied phenotype that were 331 concordant in two populations. Finally, while all individuals with multiple cancers were included in 332 our study regardless of genetic ancestry, non-European ancestries were underrepresented; 333 larger, more diverse cohorts will be needed to fully explore the genetic basis of multiple cancers. 
medRxiv preprint doi: https://doi.org/10.1101/2022.02.11.22270688; this version posted February 15, 2022. The copyright holder for this preprint (which was not certified by peer review) is the author/funder, who has granted medRxiv a license to display the preprint in perpetuity.

It is made available under a CC-BY-NC 4.0 International license .

335 Strengths of this work include studying individuals of multiple ancestries who were largely

336 unselected for specific cancer phenotypes. We also performed the first ever exome-wide study

337 of genetic susceptibility to multiple primary cancers, using two large prospective study

338 populations. Our study design allowed us to characterize variation across multiple primary

339 cancers representing 36 unique sites, as well as to conduct cancer-specific analyses of 16 sites.

340 Using this approach, we confirmed many known single-variant and gene-based findings,

341 strengthening and supporting our novel results reported for individual cancers through our cancer-

342 specific analyses.

344 In summary, by undertaking an exome-wide survey of common and rare variation in two large

345 study populations, we identified several variant and gene-based associations that may increase

346 the risk of developing multiple cancers within individuals. Our findings have potential implications

347 for improving our understanding of the shared mechanisms of carcinogenesis. They may also

348 enable screening strategies that prioritize individuals at risk for developing additional cancers.

349 Furthermore, since many of the genes reported here have been considered as potential

350 therapeutic targets in cancer, our work supports the use of germline information to help guide

351 precision medicine. Future studies should aim to replicate our findings and undertake experiments

352 that validate the functionality of the discovered pleiotropic variants. Combined with future

353 research, our results have potential to inform genetic counseling, improve risk prediction for

354 multiple cancers, and guide novel treatment and drug development. 


\section{SUPPLEMENTAL DATA}

Supplements_Tables.xls

\section{ACKNOWLEDGEMENTS}

This material is based upon work supported by NIH grant R01 CA201358, RC2 AG036607, and the National Science Foundation Graduate Research Fellowship Program under Grant No. 1650113. Any opinions, findings, and conclusions or recommendations expressed in this material are those of the author(s) and do not necessarily reflect the views of the National Science Foundation. Support for study enrollment, survey administration, and biospecimen collection of Kaiser Permanente Research Bank participants was provided by the Robert Wood Johnson Foundation, the Wayne and Gladys Valley Foundation, the Ellison Medical Foundation, and Kaiser Permanente national and regional community benefit programs. Additionally, REG is supported by a Young Investigator Award from the Prostate Cancer Foundation. This research has been conducted using the UK Biobank Resource under Application Number 14015. Furthermore, the authors thank the Regeneron Genetics Center for covering the costs of wholeexome sequencing of the Kaiser Permanente Research Bank study participants. 


\section{REGENERON GENETICS CENTER AUTHOR LIST AND CONTRIBUTION}

\section{RGC Management and Leadership Team}

Goncalo Abecasis, D.Phil. , Aris Baras, M.D., Michael Cantor, M.D., Giovanni Coppola, M.D. , Andrew Deubler , Aris

Economides, Ph.D. , Katia Karalis, Ph.D. , Luca A. Lotta, M.D., Ph.D. , John D. Overton, Ph.D., Jeffrey G. Reid, Ph.D. , Katherine Siminovitch, M.D. , Alan Shuldiner, M.D.

\section{Sequencing and Lab Operations}

Christina Beechert, Caitlin Forsythe, M.S., Erin D. Fuller, Zhenhua Gu, M.S. , Michael Lattari , Alexander Lopez, M.S., John D. Overton, Ph.D., Maria Sotiropoulos Padilla, M.S., Manasi Pradhan, M.S., Kia Manoochehri, B.S. , Thomas D. Schleicher, M.S., Louis Widom, Sarah E. Wolf, M.S., Ricardo H. Ulloa, B.S.

\section{Clinical Informatics}

Amelia Averitt, Ph.D., Nilanjana Banerjee, Ph.D., Michael Cantor, M.D., Dadong Li, Ph.D., Sameer Malhotra, M.D. , Deepika Sharma, MHI, Jeffrey Staples, Ph.D.

\section{Genome Informatics}

Xiaodong Bai, Ph.D., Suganthi Balasubramanian, Ph.D., Suying Bao, Ph.D., Boris Boutkov, Ph.D., Siying Chen, Ph.D., Gisu Eom, B.S., Lukas Habegger, Ph.D., Alicia Hawes, B.S., Shareef Khalid, Olga Krasheninina, M.S. , Rouel Lanche, B.S., Adam J. Mansfield, B.A., Evan K. Maxwell, Ph.D., George Mitra, B.A., Mona Nafde, M.S. , Sean O'Keeffe, Ph.D., Max Orelus, B.B.A., Razvan Panea, Ph.D., Tommy Polanco, B.A. , Ayesha Rasool, M.S. , Jeffrey G. Reid, Ph.D. , William Salerno, Ph.D. , Jeffrey C. Staples, Ph.D., Kathie Sun, Ph.D., Jiwen Xin, Ph.D.

\section{Analytical Genomics and Data Science}

Goncalo Abecasis, D.Phil. , Joshua Backman, Ph.D., Amy Damask, Ph.D. , Lee Dobbyn, Ph.D., Manuel Allen Revez Ferreira, Ph.D. , Arkopravo Ghosh, M.S., Christopher Gillies, Ph.D. , Lauren Gurski, B.S. , Eric Jorgenson, Ph.D. , Hyun Min Kang, Ph.D., Michael Kessler, Ph.D., Jack Kosmicki, Ph.D. , Alexander Li , Ph.D., Nan Lin, Ph.D. , Daren Liu, M.S., Adam Locke, Ph.D., Jonathan Marchini, Ph.D., Anthony Marcketta, M.S. , Joelle Mbatchou, Ph.D. , Arden Moscati, Ph.D., Charles Paulding, Ph.D., Carlo Sidore, Ph.D., Eli Stahl, Ph.D., Kyoko Watanabe, Ph.D., Bin Ye, Ph.D. , Blair Zhang, Ph.D. , Andrey Ziyatdinov, Ph.D.

\section{Research Program Management \& Strategic Initiatives}

Marcus B. Jones, Ph.D., Jason Mighty, Ph.D. , Lyndon J. Mitnaul, Ph.D. 


\section{WEB RESOUCES}

\section{REGENIE}

SnpEff

ANNOVAR

dbNSFPv3.5

flashPCA2

bcftools

plink

\section{DATA AVAILABILITY}

All results from this study are available from the article or Supplementary Materials. The UK Biobank cohort data is publicly available from the UK Biobank access portal at https://www.ukbiobank.ac.uk. The Kaiser Permanente Research Bank data are available on $\mathrm{dbGAP}$. All remaining relevant data are available in the article, supplementary information, or from the corresponding author upon reasonable request. 


\section{REFERENCES}

1. Vogt, A. et al. Multiple primary tumours: challenges and approaches, a review. ESMO Open 2, e000172 (2017).

2. Copur, M. S. \& Manapuram, S. Multiple Primary Tumors Over a Lifetime. Oncology (Williston Park) 33, 629384 (2019).

3. Gaspar, T. B. et al. Telomere Maintenance Mechanisms in Cancer. Genes 9, 241 (2018).

4. Smedby, K. E. et al. GWAS of Follicular Lymphoma Reveals Allelic Heterogeneity at 6p21.32 and Suggests Shared Genetic Susceptibility with Diffuse Large B-cell Lymphoma. PLoS Genet 7, e1001378 (2011).

5. Karnes, J. H. et al. Phenome-wide scanning identifies multiple diseases and disease severity phenotypes associated with HLA variants. Sci. Transl. Med. 9, eaai8708 (2017).

6. Huppi, K., Pitt, J. J., Wahlberg, B. M. \& Caplen, N. J. The 8q24 Gene Desert: An Oasis of Non-Coding Transcriptional Activity. Front. Gene. 3, (2012).

7. Rashkin, S. R. et al. Pan-cancer study detects genetic risk variants and shared genetic basis in two large cohorts. Nat Commun 11, 4423 (2020).

8. Lindström, S. et al. Quantifying the Genetic Correlation between Multiple Cancer Types. Cancer Epidemiol Biomarkers Prev 26, 1427-1435 (2017).

9. Hoffmann, T. J. et al. Imputation of the Rare HOXB13 G84E Mutation and Cancer Risk in a Large Population-Based Cohort. PLoS Genet 11, e1004930 (2015).

10. Szustakowski, J. D. et al. Advancing Human Genetics Research and Drug Discovery through Exome Sequencing of the UK Biobank.

http://medrxiv.org/lookup/doi/10.1101/2020.11.02.20222232 (2020) doi:10.1101/2020.11.02.20222232.

11. Rashkin, S. R. et al. Pan-Cancer Study Detects Novel Genetic Risk Variants and Shared Genetic Basis in Two Large Cohorts. bioRxiv 635367 (2019) doi:10.1101/635367. 
medRxiv preprint doi: https://doi.org/10.1101/2022.02.11.22270688; this version posted February 15, 2022. The copyright holder for this preprint

(which was not certified by peer review) is the author/funder, who has granted medRxiv a license to display the preprint in perpetuity.

It is made available under a CC-BY-NC 4.0 International license .

12. Graff, R. E. et al. Cross-Cancer Evaluation of Polygenic Risk Scores for 17 Cancer Types in Two Large Cohorts. http://biorxiv.org/lookup/doi/10.1101/2020.01.18.911578 (2020) doi:10.1101/2020.01.18.911578.

13. Adamo, M., Groves, C., Dickie, L. \& Ruhl, J. SEER Program Coding and Staging Manual 2021. National Cancer Institute, Bethesda, MD 20892. (2020).

14. Harris, N. L. et al. The World Health Organization Classification of Neoplasms of the Hematopoietic and Lymphoid Tissues: Report of the Clinical Advisory Committee Meeting Airlie House, Virginia, November, 1997. Hematol J 1, 53-66 (2000).

15. Abraham, G., Qiu, Y. \& Inouye, M. FlashPCA2: principal component analysis of Biobankscale genotype datasets. Bioinformatics 33, 2776-2778 (2017).

16. The 1000 Genomes Project Consortium. A global reference for human genetic variation.

Nature 526, 68-74 (2015).

17. Geisinger-Regeneron DiscovEHR Collaboration et al. Exome sequencing and characterization of 49,960 individuals in the UK Biobank. Nature 586, 749-756 (2020).

18. Yun, T. et al. Accurate, scalable cohort variant calls using DeepVariant and GLnexus. Bioinformatics 36, 5582-5589 (2021).

19. Mbatchou, J. et al. Computationally efficient whole-genome regression for quantitative and binary traits. Nat Genet 53, 1097-1103 (2021).

20. Cingolani, P. et al. A program for annotating and predicting the effects of single nucleotide polymorphisms, SnpEff: SNPs in the genome of Drosophila melanogaster strain w1118; iso2; iso-3. Fly (Austin) 6, 80-92 (2012).

21. Dong, C. et al. Comparison and integration of deleteriousness prediction methods for nonsynonymous SNVs in whole exome sequencing studies. Human Molecular Genetics 24, 2125-2137 (2015).

22. Wang, K., Li, M. \& Hakonarson, H. ANNOVAR: functional annotation of genetic variants from high-throughput sequencing data. Nucleic Acids Research 38, e164-e164 (2010). 
23. Backman, J. D. et al. Exome sequencing and analysis of 454,787 UK Biobank participants. Nature 599, 628-634 (2021).

24. Han, B. \& Eskin, E. Random-Effects Model Aimed at Discovering Associations in MetaAnalysis of Genome-wide Association Studies. The American Journal of Human Genetics 88, 586-598 (2011).

25. Viechtbauer, W. Conducting Meta-Analyses in $R$ with the metafor Package. J. Stat. Soft. 36, (2010).

26. Steensma, D. P. et al. Clonal hematopoiesis of indeterminate potential and its distinction from myelodysplastic syndromes. Blood 126, 9-16 (2015).

27. Cybulski, C. et al. CHEK2 Is a Multiorgan Cancer Susceptibility Gene. The American Journal of Human Genetics 75, 1131-1135 (2004).

28. Amos, C. I. et al. Genome-wide association study identifies novel loci predisposing to cutaneous melanoma. Hum Mol Genet 20, 5012-5023 (2011).

29. Li, H., Fei, X., Shen, Y. \& Wu, Z. Association of gene polymorphisms of KLK3 and prostate cancer: A meta-analysis. Adv Clin Exp Med 29, 1001-1009 (2020).

30. Hazelett, D. J. et al. Comprehensive functional annotation of 77 prostate cancer risk loci. PLoS Genet 10, e1004102 (2014).

31. Hutter, C. M. et al. Characterization of the association between $8 q 24$ and colon cancer: gene-environment exploration and meta-analysis. BMC Cancer 10, 670 (2010).

32. Wu, Y. et al. Identification of the Functions and Prognostic Values of RNA Binding Proteins in Bladder Cancer. Front. Genet. 12, 574196 (2021).

33. Herold, N. et al. With me or against me: Tumor suppressor and drug resistance activities of SAMHD1. Experimental Hematology 52, 32-39 (2017).

34. Martinez-Lopez, A. et al. SAMHD1 deficient human monocytes autonomously trigger type I interferon. Molecular Immunology 101, 450-460 (2018). 
35. Mauney, C. H. \& Hollis, T. SAMHD1: Recurring roles in cell cycle, viral restriction, cancer, and innate immunity. Autoimmunity 51, 96-110 (2018).

36. Clifford, R. et al. SAMHD1 is mutated recurrently in chronic lymphocytic leukemia and is involved in response to DNA damage. Blood 123, 1021-1031 (2014).

37. Shi, C. et al. Hypermethylation of N-Acetyltransferase 1 Is a Prognostic Biomarker in Colon Adenocarcinoma. Front. Genet. 10, 1097 (2019).

38. Tiang, J. M., Butcher, N. J., Cullinane, C., Humbert, P. O. \& Minchin, R. F. RNAi-Mediated Knock-Down of Arylamine N-acetyltransferase-1 Expression Induces E-cadherin UpRegulation and Cell-Cell Contact Growth Inhibition. PLoS ONE 6, e17031 (2011).

39. Minchin, R. F. \& Butcher, N. J. Trimodal distribution of arylamine N-acetyltransferase 1 mRNA in breast cancer tumors: association with overall survival and drug resistance. BMC Genomics 19, 513 (2018).

40. McKay, J. D. et al. Sequence Variants of NAT1 and NAT2 and Other Xenometabolic Genes and Risk of Lung and Aerodigestive Tract Cancers in Central Europe. Cancer Epidemiology Biomarkers \& Prevention 17, 141-147 (2008).

41. kConFab Investigators et al. Genome-wide association study identifies 32 novel breast cancer susceptibility loci from overall and subtype-specific analyses. Nat Genet 52, 572-581 (2020).

42. Zhang, H. et al. NCBP1 promotes the development of lung adenocarcinoma through upregulation of CUL4B. J Cell Mol Med 23, 6965-6977 (2019).

43. Wang, L. et al. Novel RNA-Affinity Proteogenomics Dissects Tumor Heterogeneity for Revealing Personalized Markers in Precision Prognosis of Cancer. Cell Chemical Biology 25, 619-633.e5 (2018).

44. Kravtsova-Ivantsiv, Y. et al. Excess of the NF-kB p50 subunit generated by the ubiquitin ligase KPC1 suppresses tumors via PD-L1- and chemokines-mediated mechanisms. Proc Natl Acad Sci USA 117, 29823-29831 (2020). 
medRxiv preprint doi: https://doi.org/10.1101/2022.02.11.22270688; this version posted February 15, 2022. The copyright holder for this preprint

(which was not certified by peer review) is the author/funder, who has granted medRxiv a license to display the preprint in perpetuity. It is made available under a CC-BY-NC 4.0 International license.

45. Ji, L. et al. RTKN2 is Associated with Unfavorable Prognosis and Promotes Progression in Non-Small-Cell Lung Cancer. OTT Volume 13, 10729-10738 (2020).

46. Weitzel, J. N. et al. Somatic TP53 variants frequently confound germ-line testing results.

Genetics in Medicine 20, 809-816 (2018).

47. Tulstrup, M. et al. TET2 mutations are associated with hypermethylation at key regulatory enhancers in normal and malignant hematopoiesis. Nat Commun 12, 6061 (2021). 


\section{FIGURE TITLES AND LEGENDS}

Figure 1. Cancer Diagnosis Pairs Present in the Combined Study Populations

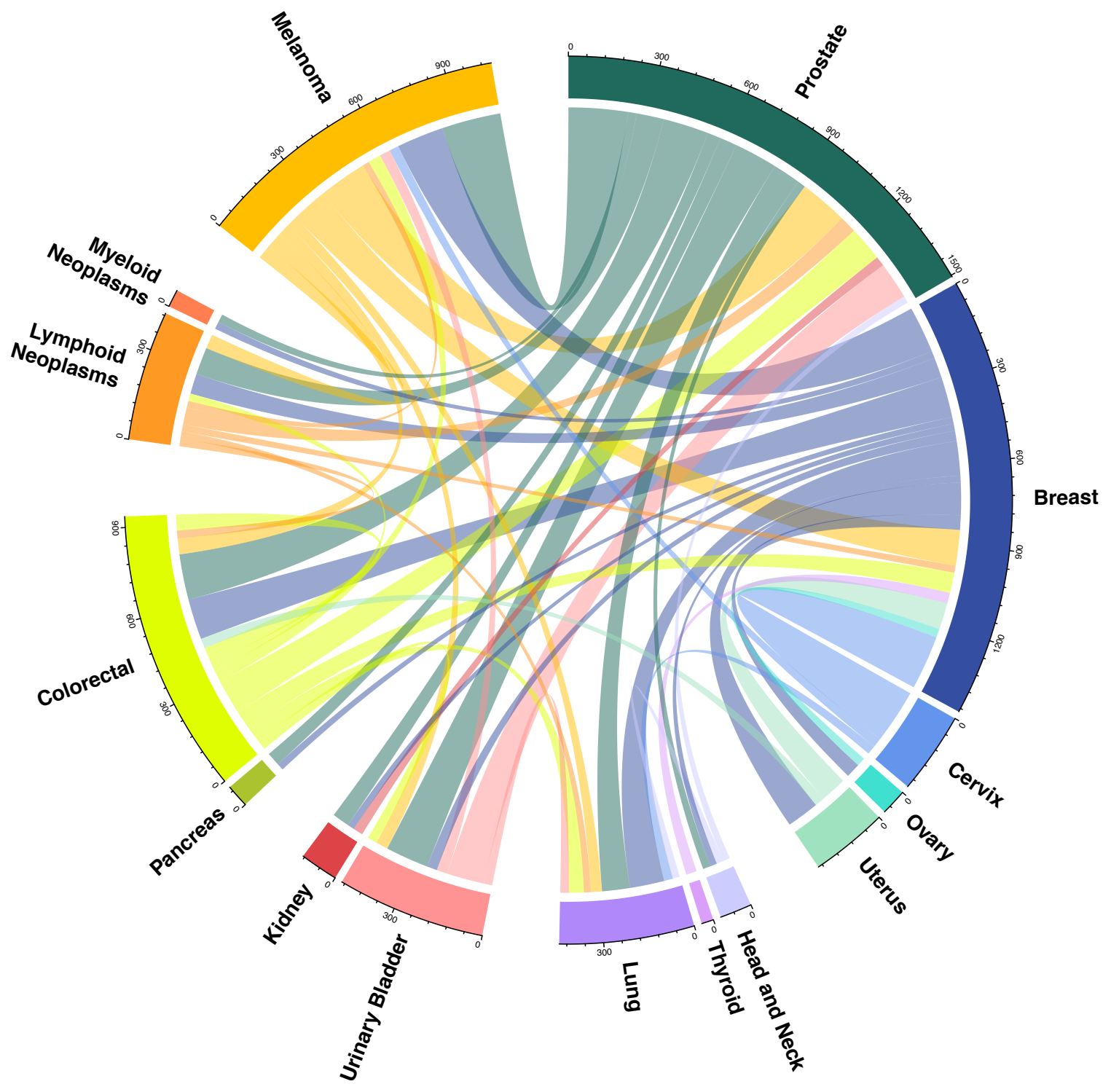

Figure 1 Legend: Circos plot describing the pairs of first and second cancer diagnoses with at least 25 cases present in Kaiser Permanente Research Bank and the UK Biobank study populations combined. Each connection reflects the number of cases with both of the linked primary cancers, where the color of the line shows the first cancer site diagnosed. 
medRxiv preprint doi: https://doi.org/10.1101/2022.02.11.22270688; this version posted February 15, 2022. The copyright holder for this preprint (which was not certified by peer review) is the author/funder, who has granted medRxiv a license to display the preprint in perpetuity.

It is made available under a CC-BY-NC 4.0 International license .

Figure 2. Germline Single Variant Association Results for Multiple Primary Cancers Combined or Grouped by Organ Site

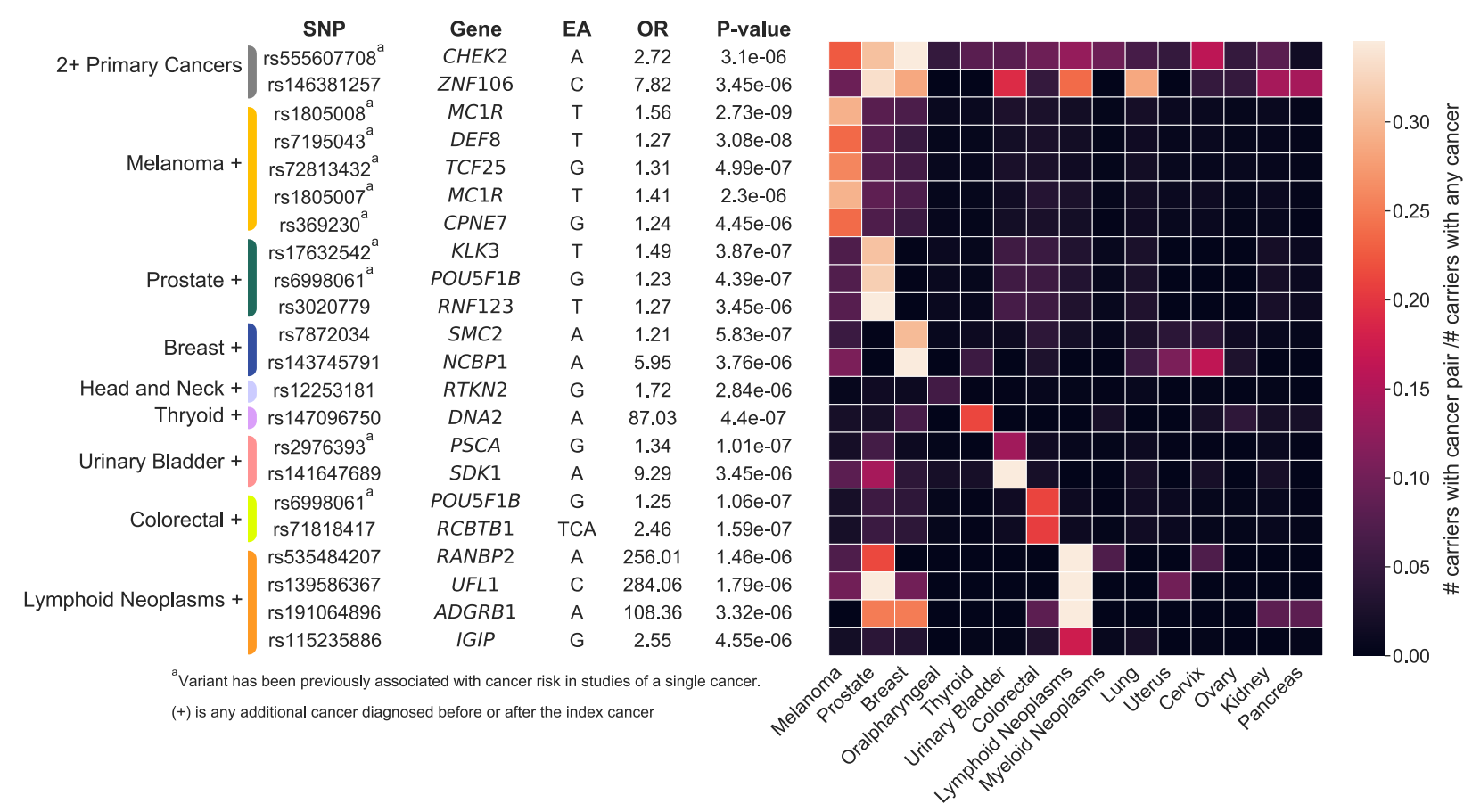

Figure 2 Legend: Suggestive $\left(p<5 \times 10^{-6}\right)$ germline variant associations with multiple cancer phenotypes versus cancer-free controls $(n=165,853)$ following a fixed-effects meta-analysis of Kaiser Permanente Research Bank and UK Biobank WES data. Associations were detected for any $2+$ primary cancers $(n=6,429)$ and with groups of cases defined by a shared index cancer, at any time point, plus any other cancer diagnosis: melanoma $+(n=1,443)$, prostate $+(n=1,977)$, breast $+(n=1,874)$, head and neck $+(n=283)$, thyroid $+(n=198)$, urinary bladder $+(n=829)$, colorectal $+(n=1,324)$, lymphoid neoplasms $+(n=728)$. Variants that have been previously associated in single cancer studies have superscript (a). The heatmap reflects the number of carriers with the risk-increasing allele for each associated variant with the index $(y$-axis) and additional (x-axis) cancer over the total number of carriers, restricting to cancer cases. When the index and additional cancer are the same, the heatmap value represents all carriers with the specified cancer diagnosis divided by the total number of carriers. Abbreviations: SNP - single nucleotide polymorphism; EA - effect allele; OR - odds ratio. 
medRxiv preprint doi: https://doi.org/10.1101/2022.02.11.22270688; this version posted February 15, 2022. The copyright holder for this preprint (which was not certified by peer review) is the author/funder, who has granted medRxiv a license to display the preprint in perpetuity.

It is made available under a CC-BY-NC 4.0 International license.

Figure 3. Germline Gene Based Association Results for Multiple Primary Cancers Combined or Grouped by Organ Site

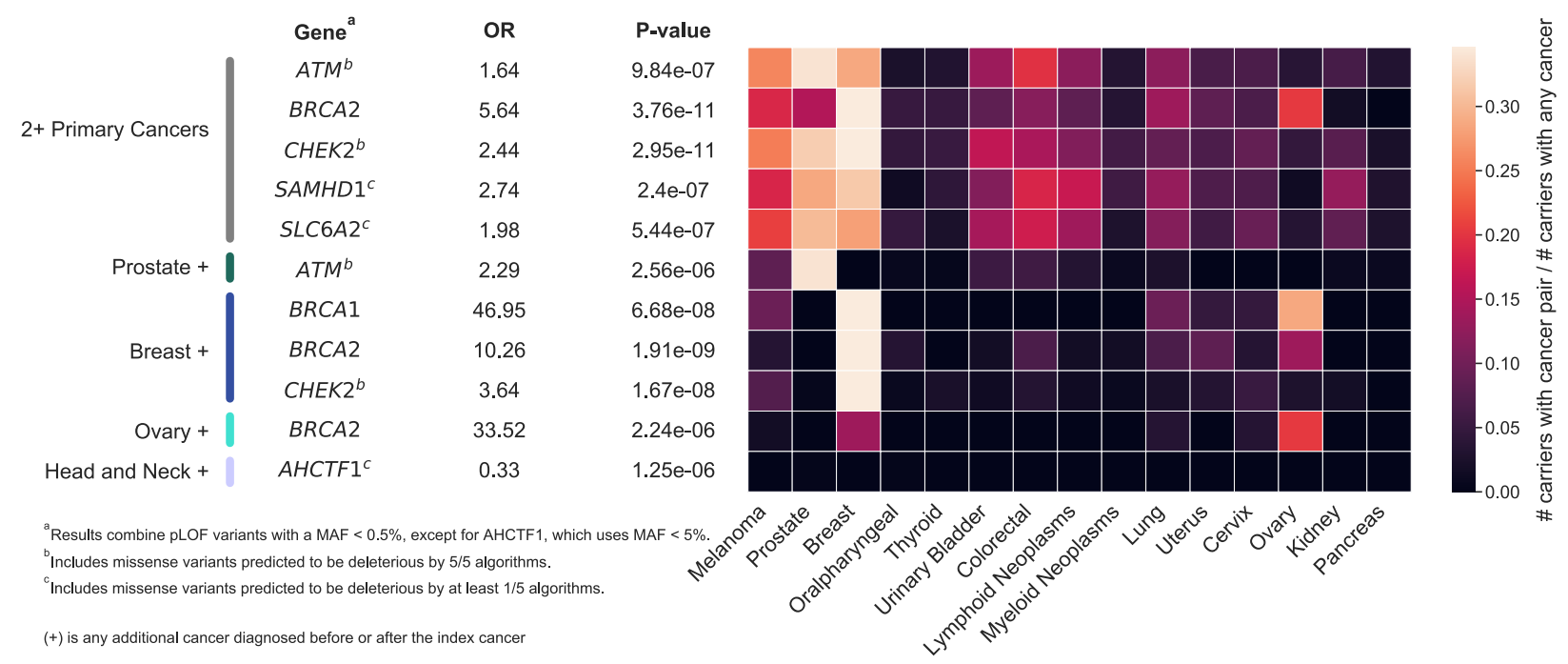

Figure 3 Legend: Burden tests were performed combining variants defined as pLOF with or without deleterious missense variants, defining deleteriousness by at least one $(1 / 5)$ or all five $(5 / 5)$ prediction algorithms used (Methods), at a MAF $<0.5 \%, 1 \%$, or $5 \%$. Following a fixed-effects meta-analysis of Kaiser Permanente Research Bank and UK Biobank data, Bonferroni significant associations $\left(p<2.65 \times 10^{-6}=0.05 / 18,842\right)$ corrected for the number of genes tested were found for comparisons of cancer-free controls $(n=165,853)$ with all cases with any $2+$ primary cancers $(n=6,429)$ and with groups of cases defined by an index cancer for the following phenotypes: prostate $+(n=1,977)$, breast $+(n=1,874)$, ovary $+(n=239)$, and head and neck $+(n=283)$. For each gene, the variant grouping with the smallest $p$-value and fewest number of variants was selected. The heatmap reflects the number of carriers of each associated variant, with the index (y-axis) and additional (x-axis) cancer over the total number of carriers, where carrier is defined as having at least one alternate allele across all variants in a given gene, restricting to cancer cases. When the index and additional cancer are the same, the heatmap value represents all carriers with the specified cancer diagnosis divided by the total number of carriers. Abbreviations: OR - odds ratio; pLOF - predicted loss of function. 


\section{TABLES}

Table 1. Characteristics of the Kaiser Permanente Research Bank and UK Biobank study populations by ancestry group. Cases are individuals with multiple primary cancers. Controls are those without any cancer.

\begin{tabular}{|c|c|c|c|c|c|c|}
\hline \multirow[b]{3}{*}{ Ancestry } & \multicolumn{6}{|c|}{ Population: Kaiser Permanente Research Bank } \\
\hline & \multicolumn{3}{|c|}{ Cases } & \multicolumn{3}{|c|}{ Controls } \\
\hline & $\mathrm{N}$ & $\begin{array}{c}\text { Mean } \\
\text { Age }\end{array}$ & $\begin{array}{c}\text { Female } \\
(\%)\end{array}$ & $\mathrm{N}$ & $\begin{array}{c}\text { Mean } \\
\text { Age }\end{array}$ & $\begin{array}{c}\text { Female } \\
(\%)\end{array}$ \\
\hline AFR & 99 & 70.5 & 33.3 & 100 & 70.4 & 32.0 \\
\hline EAS & 95 & 69.7 & 49.5 & 91 & 69.5 & 49.5 \\
\hline EUR & 2,786 & 72.8 & 43.0 & 2815 & 72.9 & 43.3 \\
\hline LAT & 131 & 69.5 & 46.6 & 130 & 69.5 & 45.4 \\
\hline SAS & - & - & - & - & - & - \\
\hline
\end{tabular}

\begin{tabular}{cccccc}
\hline \multicolumn{4}{c}{ Population: UK Biobank } \\
\hline \multicolumn{3}{c}{ Cases } & \multicolumn{3}{c}{ Controls } \\
\hline $\mathrm{N}$ & $\begin{array}{c}\text { Mean } \\
\text { Age }\end{array}$ & $\begin{array}{c}\text { Female } \\
(\%)\end{array}$ & $\mathrm{N}$ & $\begin{array}{c}\text { Mean } \\
\text { Age }\end{array}$ & $\begin{array}{c}\text { Female } \\
(\%)\end{array}$ \\
\hline 29 & 55.9 & 51.7 & 3,292 & 51.8 & 60.4 \\
10 & 58.8 & 80.0 & 1,009 & 52.6 & 66.9 \\
3,249 & 61.9 & 51.7 & 154,047 & 56.6 & 54.6 \\
5 & 63.8 & 80.0 & 334 & 51.8 & 62.6 \\
25 & 58.2 & 60.0 & 4,035 & 53.3 & 47.0 \\
\hline
\end{tabular}

